\title{
Die Eosinreaktion des Glases an Bruchflächen.
}

\author{
Von \\ F. Mruids.
}

(Mitteilung aus der Physik. Techn. Reichsanstalt.)

Mit 9 Figuren im Text und 1 Tafel.

Jedes homogene Glas ist durch seine Zusammensetzung chemisch definiert; dagegen ist es bis jetzt nicht gelungen, die Reaktionsfähigkeit einer Glasart zahlenmälsig zu bestimmen; und doch würde dies zu einer chemischen Charakterisierung des Glasmateriales führen, welche für manche $Z$ wecke wertvoller sein kann als die Kenntnis seiner Zusammensetzung.

Flüssige Reagenzien wirken auf verschiedene Arten von Glas bekanntlich mit ungleicher Geschwindigkeit ein; am ausführlichsten ist die Wirkung des Wassers untersucht; dabei wurde die Grösse und Beschaffenheit der Oberfläche aber nicht genügend berücksichtigt. Die wirkende Oberfläche war entweder unbekannt, wie bei zahlreichen Versuchen mit Glaspulvern, oder sie war bekannt, wie bei der in der Technik gebräuchlichen Prüfung geblasener Glasgeräte. Im letzteren Falle hat man es aber keineswegs mit dem unveränderten Glase zu tun, sondern mit Oberflächenschichten, welche durch Verdampfen von Alkali beim Blasen in der Hütte, Einwirkung schwefliger Säure in den Kühlräumen, durch Verminderung des Alkalis bei der Verwitterung, durch Schleifen der Geräte oder durch Abspülen derselben verändert waren.

Derartige vergleichende Untersuchungen können für die Technik der Glasgeräte sehr wichtig sein, ohne über das Verhalten der Glasart, welche zu ihrer Herstellung gedient hat, etwas auszusagen.

Im Gegensatz zu der Untersuchung einzelner Glasgegenstände mit veränderten Oberflächenschichten soll in dieser Mitteilung von der Reaktionsfähigkeit der ursprünglichen Glasarten die Rede sein.

Die Beobachtungen geschahen ausschliefslich an Bruchflächen von melsbarer Grölse.

z. anorg. Chem. Bd. 55 . 
Quantitative Bestimmungen über die Wirkung von Wasser auf Glas werden in neuerer Zeit häufig so ausgeführt, dafs man dasselbe mit reinem Wasser in Reaktion setzt und das hydrolytisch gebildete Alkali in der Lösung kolorimetrisch bestimmt. Zu diesem Zweck wird dieselbe mit ätherischer Lösung ron Jodeosin durchschüttelt. Aus der Farbenintensität der roten wässerigen Schicht kann die Menge des nunmehr an die Eosinsäure gebundenen Alkalis leicht abgeschätzt werden.

Von F. Foerster und mir ${ }^{1}$ sind auf diesem Wege schon vor längerer Zeit zahlreiche Versuchsreihen durchgeführt worden.

Wo die Wirkung des Wassers, wie im gegenwärtigen Fall, auf die Bruchfläche eines Glasstückes beschränkt werden soll, wird ein kürzeres Verfahren vorgezogen, bei welchem man die Wirkung des Wassers und des Farbstoffes nicht in getrennten. Operationen, sondern zu einer Reaktion vereinigt vornimmt.

Man setzt das Glasstück direkt der Wirkung feuchter ätherischer Eosinlösung aus. Dabei wirkt das gelöste Wasser zersetzend auf das Glas ein, und das gebildete Alkali fixiert sogleich eine äquivalente Menge des sauren Jodeosins. Da die so erzeugten Alkalisalze $\mathrm{Na}_{2}\left(\mathrm{C}_{20} \mathrm{H}_{6} \mathrm{~J}_{4} \mathrm{O}_{5}\right)$ resp. $\mathrm{K}_{2}\left(\mathrm{C}_{20} \mathrm{H}_{6} \mathrm{~J}_{4} \mathrm{O}_{5}\right)$ in Äther unlöslich sind, erscheinen sie auf der Glasoberfläche als rotgefärbter, in Wasser leicht löslicher Überzug.

Diese einfache "Eosinprobe" ist von mir bereits 1888 zur Unterscheidung verschiedenen Glasmaterials empfohlen ${ }^{2}$ und in der geschilderten Form seitdem in der Technik vielfach benutzt worden, jedoch fast ausschliefslich zur qualitativen Vergleichung von Glasröhren, aus deren geringer oder stärkerer Rotfärbung man Schlufsfolgerungen auf die chemische Beschaffenheit der Gläser zu ziehen wünscht.

Naturgemäls wird es möglich sein, die Eosinprobe in dieser Form auch für zahlenmälsige Angaben nutzbar zu machen. Der Grund, weswegen dies bisher unterblieben ist, liegt in der Unkenntnis der analytischen Fehlerquellen, welche um so stärker ins Gewicht fallen, je kleiner die kenntlich zu machenden Alkalimengen sind.

1 Myuius und Foenster, Ber. deutsch. chem. Ges. 24 I (1891), 1482; Zeitschr. analyt. Chem. 31 (1892), 241. - Foenster, Zeitschr. analyt. Chem. 33 (1894), 299, 323-381. - Mruıus, Ber. V. Int. Kongr. f. angew. Chem. 1903, Band I, S. 1.

${ }^{2}$ F. Myuros, Zeitschr. f. Instrwmentenk. 8 (1888), 269; 9 (1889), 50; Ber. deutsch. chem. Ges. 22 I (1889), 311. 
Soll das angedeutete Beizverfahren zu quantitativen Versuchen über die hydrolytischen Reaktionen an Bruchflächen der Gläser Anwendung finden, so bedarf die Methode eines eingehenden Studiums, bevor ein Urteil über den Grad ihrer Brauchbarkeit gefällt werden kann.

Die Gestalt und Abgrenzung der Bruchflächen, die Beschaffenheit der ätherischen Lösung, Fehler bei der kolorimetrischen Vergleichung und andere Einflüsse können die Versuchsergebnisse bei kritikloser Handhabung des Verfahrens völlig wertlos machen.

In den folgenden Blättern behandelt der Abschnitt $\mathrm{A}$ die Handhabung der Eosinprobe, der kürzere Abschnitt B das Ergebnis bei der Anwendung auf verschiedene Arten von Glas (S. 251).

\section{A. Die Handhabung der Eosinprobe.}

\section{Die Reagenzien.}

1. Reines Jodeosin, Erythrosin oder Tetrajodfluoresceyn vom Schema $\mathrm{C}_{20} \mathrm{H}_{8} \mathrm{~J}_{4} \mathrm{O}_{5}$ dient als Grundlage. Das käufliche Präparat ist stets verunreinigt; die Reinigung geschieht nach früherer Angabe ${ }^{1}$ mit Hilfe des aus verdünntem Alkohol umzukrystallisierenden Natriumsalzes.

Eine sehr kleine Menge von Asche, welche das gereinigte Produkt bisweilen enthält, ist bei der Herstellung der Lösungen meist zu vernachlässigen. Das Präparat ist in der krystallisierten Beschaffenheit zu verwenden, in welcher ein Gramm bei Zimmer: temperatur etwa 3 Liter wässerigen Äthers zur Auflösung gebraucht. Wesentlich stärkere Lösungen erhält man aus frischgefälltem, amorphem Material; aus solchen ,übersättigten" Lösungen kann der Farbstoff langsam auskrystallisieren.

Mischungen von beiden Modifikationen werden durch Ausziehen mit Äther von der amorphen Substanz befreit und dann bei $100^{\circ}$ getrocknet. Das krystallisierte Jodeosin stellt ein matt ziegelrotes Pulver dar.

2. Äther wird in zwei Zuständen gebraucht, wasserreich und wasserarm. Da der käufliche Äther leicht sauer wird, ist er mit verdünnter Alkalilösung und darauf mit Wasser zu schütteln. Das bei $18^{\circ}$ aufgenommene Wasser läist sich durch Ausfrieren in einer Kältemischung leicht zum grölsten Teil wieder beseitigen. Diese Art

${ }^{1}$ Mrufos und Foerster, Ber. deutsch. chem. Ges. 24 I (1891), 1482. 
der Reinigung ist oft zweckmälsiger als die Destillation. Wasserbaltiger Äther, welcher in einer völlig gefüllten Flasche mit geglühter Soda in Pulverform geschüttelt wird, verliert Wasser und nimmt eine Spur Alkali auf. Derartiger Äther dient zum Abspülen der gebeizten Glasstücke.

3. Das destillierte Wasser soll womöglich neutral sein; in Glasflaschen wird es ein wenig alkalisch; bisweilen ist es kaum merklich sauer, nach freundlicher Angabe des Herrn Dr. Banvow von Humussäuren herrührend. Das käufliche destillierte Wasser ergibt manchmal festhaftende Algenvegetationen am Boden der Glasflaschen.

Alle diese Verunreinigungen sind für den vorliegenden Zweck unschädlich; die herzustellenden wässerigen Lösungen enthalten meist überschüssiges Alkali.

4. Ätherische Eosinlösung. Die als Reagens verwendete Lösung soll $0.5 \mathrm{~g}$ Jodeosin im Liter enthalten. Obwohl eine solche Lösung in bezug auf das krystallisierte Eosin übersättigt ist, hält sie sich in verschlossener dunkler Flasche monatelang ohne wesentliche Veränderung. Allmähliches Auskrystallisieren des Farbstoffes kann im Laufe der Zeit den Gehalt etwas verringern.

Mälsige Änderungen in der Konzentration sind nicht schwerwiegend für das Ergebuis der Versuche.

Zur Herstellung der Lösung wird $0.5 \mathrm{~g}$ Jodeosin in einer Stöpselflasche in $13 \mathrm{ccm} 1 / 10^{-n o r m}$. Natronlauge gelöst, und die Lösung nach Hinzufügen von $120 \mathrm{ccm}$ Wasser mit $15 \mathrm{ccm} 1 / 10^{-n o r m}$. Schwefelsäure versetzt, wodurch der Farbstoff zur Ausscheidung gelangt. Die gelbrote Mischung ist jetzt mit einem Liter wasserhaltigen Äthers kräftig durchzuschütteln, bis der Farbstoff gelöst ist. Die Trennung der Schichten bewirkt man in einem Scheidetrichter und wäscht die ätherische Schicht dreimal mit je $30 \mathrm{ccm}$ Wasser; das Waschwasser ist zuletzt stark rotgefärbt.

Die ätherische Eosinlösung ist in möglichst gefüllten Flaschen aus gutem Glase in dunklem Schrank aufzubewahren. Frisches Glas entzieht der Lösung Eosin, Licht und Luft macht sie sauer. Soll der Farbstoffgehalt bestimmt werden, so löst man $10 \mathrm{ccm}$ der ätherischen Eosinlösung in alkalischem Wasser zum Liter auf und vergleicht diese Lösung kolorimetrisch mit der alkalischen Standardlösung 6 .

5. Reagens von konstanter Empfindlichkeit. Einwirkung von Luft und Licht raubt dem Reagens seine Empfindlichkeit. 
Eine Lösung, welche ein halbes Jahr lang in halbgefüllter Flasche am Licht gestanden hat, ist nicht mehr imstande, die Verwitterungsschicht in den gewöhnlichen Reagierröhren sofort kenntlich zu machen, was von einer empfindlichou Lösung unbedingt zu verlangen ist.

Die Prüfung der verdorbenen Lösung ergab neben dem unveränderten Jodeosin einen Gehalt an starker Säure, welcher 4 Zentigramm Ameisensäure im Liter äquivalent war.

Alkalimetrische Bestimmungen mit einer solchen Lösung würden für den vorliegenden $Z_{\text {weck }}$ vollkommen aussichtslos sein, wenn es nicht Mittel gäbe, die verlorengegangene Empfindlichkeit der reagierenden Flüssigkeit wieder herzustellen und auf gleicher Höhe zu erhalten.

Das Mittel besteht einfach in der Behandlung mit dem Natriumsalz des Jodeosins, welches in wässeriger einprozentiger hösung zur Anwendung gelangt. Bei dem Schütteln mit dieser Lösung tritt eine Umsetzung ein, indem die starke Säure durch das Natron gebunden, und eine äquivalente Menge freien Eosins in die ätherische Lösung übergeführt wird. Die dadurch bedingte Erhöhung der Farbstofflionzentration ist unwesentlich, die Empfindlichkeit der Lösung zum Nachweis von Alkali hat aber ein Maximum erreicht, so dafs die alkalische Oberfläche eines Reagierrohres leicht kenntlich gemacht werden kann. Die folgenden Versuche dienten dazu, die Veränderung, welche die Oxydation des Äthers in der Lösung bewirkt, noch näher abzuschätzen.

a) Zur Unterscheidung von reinem und sauerstoffhaltigem Äther kann Quecksilber dienen, welches man in völlig geschlossener Flasche damit schüttelt. Im ersteren Fall bleibt die Oberfläche des Quecksilbers glänzend, im letzteren überzieht sie sich mit einer Schicht von schwarzem Oxydul.

Ein Luftgehalt in der Flasche lärst auch bei dem Schütteln mit reinem Äther sogleich Oxydulhäute auf dem Quecksilber entstehen. Enthält der Äther Eosin, so bilden sich an Stelle des Quecksilberoxyduls violett gefärbte Farbstoffsalze.

b) Es ist bekannt, dals Äther durch Sauerstoff zunächst in sehr aktive superoxydartige Stoffe verändert wird, welche dann zur Säurebildung Veranlassung geben.

Ameisensäure und Essigsäure kommen hier in Betracht; ihre Menge ist aber auf den gebräuchlichen Wegen schwer bestimmbar. $\mathrm{Da}$ das Jodeosin ebenfalls den Charakter einer Säure besitzt, so 
war es fraglich, wie es sich im Vergleich zur Essigsäure verhalten würde.

Ein System von $10 \mathrm{ccm} \mathrm{1 \%}$ iger Jodeosin-Natriumlösung und $100 \mathrm{ccm}$ Äther wurde mit $1 \mathrm{mg}$ Kssigsäure versetzt und geschüttelt. Die nunmehr gelbgefärbte ätherische Schicht enthielt jetzt $7 \mathrm{mg}$ Jodeosin, welcher $0.9 \mathrm{mg}$ Essigsäure äquivalent sind. Wiederholter Zusatz von Essigsäure hatte eine ähnliche Steigerung des Farbstoffgehaltes zur Folge.

Daraus geht hervor, dafs Essigsäure bei Gegenwart von Äther das Eosin aus seinen Alkalisalzen leicht verdrängt; auf die angedeutete Weise ist daher ein Säuregehalt des Äthers leicht abzuschätzen, und das Verfahren mag gelegentlich auch zu Bestimmungen von Spuren anderer Säuren in wässeriger Lösung ebenso anwendbar sein wie die ätherische Eosinlösung in der Alkalimetrie.

c) Äther, mit 1\% iger Lösung von Jodeosinnatrium geschüttelt, erscheint farblos und ist merklich frei von Farbstoff. Wurde eine solche Mischung in halbgefüllter farbloser Flasche dem wechselnden, zeitweise sonnigen Tageslicht ausgesetzt und gelegentlich geschüttelt, so färbte sich die ätherische Schicht mehr und mehr gelb; der nunmehr vorhandene Gehalt an Eosin nahm stetig zu und erreichte nach 10 Tagen $0.08 \mathrm{~g}$ für das Liter, äquivalent $8 \mathrm{mg}$ Ameisensäure. Nach einem Monat betrug der Gehalt $0.3 \mathrm{~g}$ Jodeosin; die Lösung war nunmehr dunkelgelb gefärbt und stark alkaliempfindlich.

Eine an der Grenze der beiden Schichten entstandene, fortgesetzt zunehmende Trübung wird auf die Bildung eines Oxydationsproduktes des Farbstoffes zurückgeführt, welches die Empfindlichkeit der Lösung nicht merklich beeinträchtigt.

Eine nähere Untersuchung des bräunlichen, in Äther fast unlöslichen Oxydationsproduktes vom Jodeosin hat nicht stattgefunden, da seine Bildung nur bei absichtlich starker Belichtung erfolgt; eine solche, zumal die direkte Bestrahlung von der Sonne, kann man leicht vermeiden, und dann erweist sich die ätherische Eosinlösung sehr haltbar.

Das System von ätherischer Eosinlösung und 1\% iger Lösung von eosinsaurem Natrium ist übrigens nicht für die dauernde Aufbewahrung bestimmt; es wird für die Versuche in völlig gefüllter brauner Flasche (ca. $300 \mathrm{ccm}$ Inhalt) zur Hand gehalten; einige erbsengrofse Glasstücke erleichtern das Durchschütteln. Nach der Klärung ist die ätherische Schicht direkt in das Reaktionsgläschen abzugiefsen. 
6. Alkalische Eosinlösung zum kolorimetrischen Vergleich. Gebraucht wird eine genau eingestellte wässerige Lösung von einem Zentigramm Jodeosin als Alkalisalz in einem Liter, also dem Gewichte nach eine Verdünnung 1:100000. Wine solche Lösung ist am Licht nicht dauernd haltbar, sie mufs für jede Versuchsreihe frisch hergestellt und in schwarzer geschlossener Flasche aufbewahrt werden. Zur Orientierung über den Grad der Haltbarkeit alkalischer Jod-Eosinlösungen sind folgende Versuche angestellt worden. Das Jodeosin wurde dabei als Natriumsalz $\mathrm{Na}_{2}\left(\mathrm{C}_{20} \mathrm{H}_{6} \mathrm{~J}_{4} \mathrm{O}_{5}\right)$ benutzt; die angegebenen Verdünnungen sind gravimetrisch gemeint und beziehen sich auf freies Eosin als Alkalisalz.

\section{A. Lösung 1:100000.}

a) Im geschlossenen Kolben erfuhr die Lösung bei diffuser, durch die Nacht unterbrochener Beleuchtung und Zimmertemperatur innerhalb 10 Tagen einen Verlust von $50 \%$ der Farbenintensität.

b) In schwarzer Flasche blieb die Lösung unter den gleichen Bedingungen merklich unverändert.

c) In brauner durchscheinender Flasche fand sich bei wechselnder Beleuchtung nach einem Monat noch zwei Drittel der ursprünglichen Färbung vor.

d) Dreistündige Bestrahlung mit Sonne führte im farblosen Kolben einen Farbenverlust von $80 \%$ herbei; in brauner Flasche ergaben 5 Stunden Sonne einen Verlust von $50 \%$. In derselben Flasche sank die Färbung bei wechselnder, zum Teil sonniger Aprilbeleuchtung innerhalb von 10 Tagen auf $6 \%$ des urspründlichen Wertes herab.

e) In farbloser Flasche, mit einem Auerlichtbrenner bestrahlt, verlor die $40^{\circ}$ warme Lösung innerbalb 4 Tagen $60 \%$ ihrer Färbung.

B. Lösung $1: 10000$.

a) In schwarzer Flasche blieb die Lösung während mehrerer Monate merklich unverändert.

b) Im farblosen Kolben Tag und Nacht an einem nach Norden gehenden Fenster stehend (Ausschlufs direkter Sonnenbestrablung) erfuhr die Lösung, welche Zusätze von $0.01,0.05,0.1$ und $1.0 \%$ Natron (NaHO) erhalten hatte, die folgenden in der Kurvenzeichnung Fig. 1 veranschaulichten Verluste der Farbenintensität. 


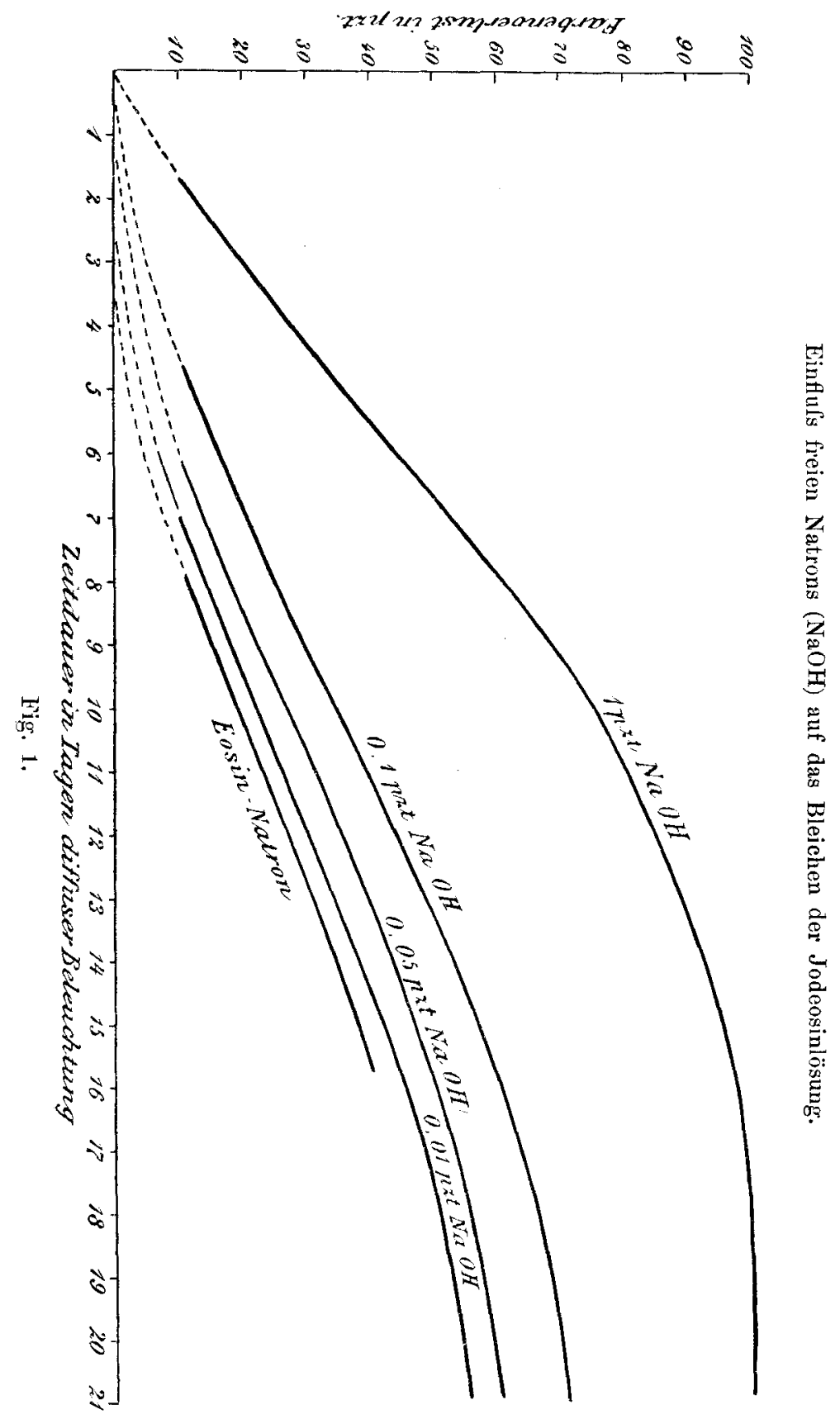


Verlust in Prozent der ursprünglichen Färbung.

\begin{tabular}{|c|c|c|c|c|c|}
\hline Zeitdauer & Lösung B & $\begin{array}{l}0.01 \% \\
\text { Natron }\end{array}$ & $\begin{array}{l}0.05 \% \\
\text { Natron }\end{array}$ & $\begin{array}{l}0.1 \% \\
\text { Natron }\end{array}$ & $\begin{array}{r}1.0 \% \\
\text { Natron }\end{array}$ \\
\hline 10 Tage & 20 & & & 35 & 75 \\
\hline $16 "$ & $\begin{array}{c}40 \\
\text { etwas Eosin } \\
\text { ausgeschieden }\end{array}$ & 45 & 50 & 60 & 97 \\
\hline 3 Wochen & 40 & 55 & 60 & 71 & 99.5 \\
\hline
\end{tabular}

Die Versuche ergeben, dafs der Bleichvorgang durch eine gröfsere Menge freien Natrons aufserordentlich beschleunigt wird.

C. Lösungen wechselnder Konzentration.

Ein' genaueres Urteil über den Einflufs der Konzentration der Farbstofflösungen auf den Bleicheffekt konnte durch die gütige Mitwirkung von Herrn Professor BRodhun gewonnen werden.

Vier in der Konzentration je um den 10 fachen Betrag wechselnde Lösungen von eosinsaurem Natrium (1 Gramm, 1 Dezigramm, 1 Zentigramm und 1 Milligramm Jodeosin im Liter) wurden in einer Dunkelkammer dauernd der Lichtwirkung eines Wolframbrenners von 25 Kerzen ausgesetzt, um welchen sie in einem Abstande von ca. $10 \mathrm{~cm}$ gruppiert waren. Die Wärmestrahlen wurden dabei durch eine $2 \mathrm{~cm}$ dicke Wasserschicht zurückgehalten, so dafs die Lösungen nur eine Temperatur von etwa $20^{\circ}$ hatten.

Man erhielt das folgende Ergebnis:

Lösung I enthielt im Liter $1.0 \mathrm{~g}$ Jodeosin.

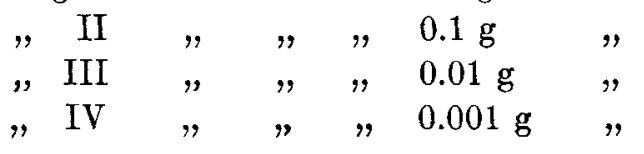

Verlust in Prozent der ursprünglichen Färbung.

\begin{tabular}{|c|c|c|c|c|}
\hline $\begin{array}{c}\text { Dauer } \\
\text { der Belichtung }\end{array}$ & $\begin{array}{c}\text { Lösung I } \\
1: 1000\end{array}$ & $\begin{array}{c}\text { Lösung II } \\
1: 10000\end{array}$ & $\begin{array}{l}\text { Lösung III } \\
1: 100000\end{array}$ & $\begin{array}{l}\text { Lösung IV } \\
1: 1000000\end{array}$ \\
\hline 4 Tage & unmerklich & 20 & 91 & 98 \\
\hline $8 \quad "$ & 3 & 35 & 96 & $\begin{array}{l}100 \\
\text { farblos }\end{array}$ \\
\hline 12 & 8 & $\begin{array}{c}50 \\
\text { getrübt }\end{array}$ & $\begin{array}{l}\text { nicht bestimmbar } \\
\text { gelbl. Farbenton }\end{array}$ & - \\
\hline
\end{tabular}

Nach einer Belichtung von 12 Tagen waren für das Auge verschwunden pro Liter: 


$$
\begin{aligned}
& \text { Bei Lösung I } \quad 0.08 \mathrm{~g} \quad \text { Jodeosin }=\quad 8 \%
\end{aligned}
$$

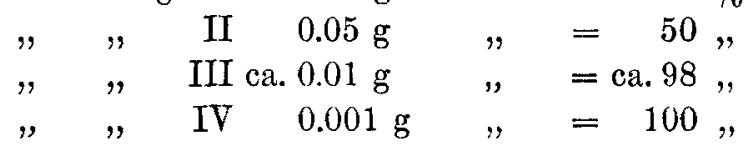

Die absolute Menge des durch die Bleichwirkung vernichteten Farbstoffes wächst also erheblich mit zunehmender Konzentration, während dieser Verlust, prozentisch betrachtet, wesentlich abnimmt. Fig. 2 zeigt die Kurven für die 4 Lösungen. Nach diesen Versuchsergebnissen ist anzunehmen, dafs die Lösungen bei noch grölserer

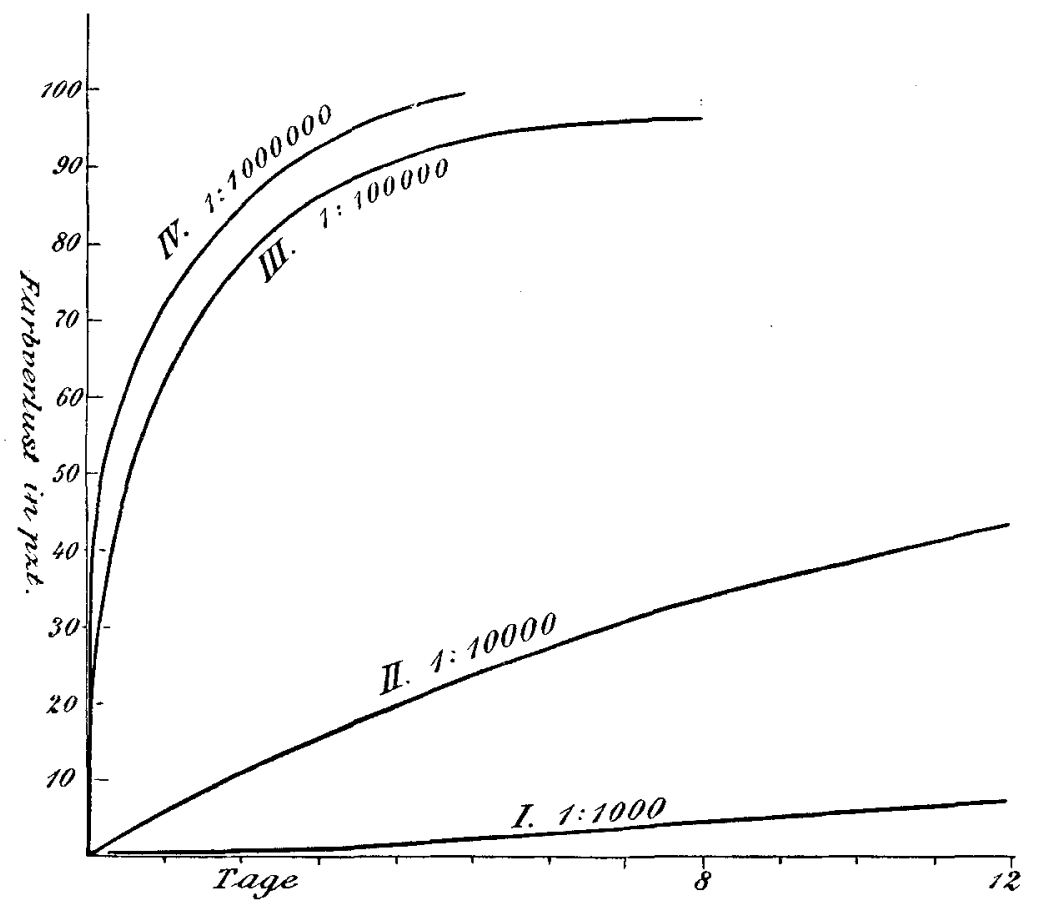

Fig. 2.

Konzentration, z. B.: 1:100 und 1:10, zwar prozentisch haltbarer werden, dafs aber die zerstörende Wirkung des Lichtes selbst bei diesen hohen Konzentrationen nicht aufgehoben ist.

D. Zur weiteren Charakterisierung des Jodeosins in kolorimetrischer Hinsicht mögen noch die folgenden Angaben dienen.

a) In Wasser ist krystallisiertes Jodeosin fast unlöslich, in Alkohol sowie in Eisessig schwer löslich. Essigsaure Lösungen sind 
(wie die ätherischen) orangegelb; durch Zufügen von Alkali und Verdünnen mit Wasser werden sie rosenrot ohne einen scharfen Übergang. Die Farbenänderung erfolgt in demselben Sinne, wenn die essigsaure Lösung mit reinem Wasser verdünnt wird.

b) Konzentrierte wässerige Lösungen vom Natronsalz des Jodeosins erscheinen im Reagierrohr gelbrot, verdünnte rosenrot; Zusatz geringer Mengen von Essigsäure zu den rosenroten Lösungen hat nur kleine Farbenänderungen zur Folge; ebenso wird durch Zusatz geringer Mengen freien Alkalis zu den verdünnten Lösungen der Farbenton nicht geändert.

c) Verdünnte rote Eosinlösungen werden bei dem Erwärmen mit konzentrierter Natronlauge blau; bei längerem Erwärmen tritt Entfärbung oder Mifsfärbung ein; die blauen Lösungen werd̉en bei der Verdünnung mit Wasser wieder rosenrot.

d) Verdünnte alkalische Jodeosinlösungen werden durch Behandlung mit schwefliger Säure oder mit Zink langsam entfärbt unter Auftreten einer grünen Fluorescenz.

Die vorstehenden Versuche bestätigen die bereits bekannte Tatsache, ${ }^{1}$ dafs alkalische Lösungen von Jodeosin durch das Licht zersetzt werden. Sie sind um so weniger beständig, je mehr das Alkali in ihnen vorwaltet und je verdünter sie sind.

Die unter Beihilfe des Lichtes vor sich gehende Zersetzung, bei welcher die Färbung für das Auge verschwindet, beruht offenbar auf der Überführung in nicht oder wenig gefärbte Produkte, welche unter Aufnahme der Elemente des Wassers entstehen mögen. In welcher Weise man sich diesen Vorgang zu denken hat, lehrt das Verhalten des Fluoresceins, welches bekanntlich die Muttersubstanz der Eosine darstellt. In saurer Mischung, durch Vereinigung von Resorcin mit Phtalsäure entstanden, hat es in alkalischer Lösung das. Bestreben, unter Aufnahme von Wasser wieder in diese Komponenten überzugehen, wobei mancherlei Zwischenprodukte möglich und isolierbar sind.

Bei den Substitutionsderivaten des Fluoresceins treten blaue vergängliche Farbstoffe auf, welche die entsprechende Spaltung vermitteln; wesentlich deutlicher als bei dem Jodeosin tritt dies bei dem gewöhnlichen Bromeosin hervor, dessen blaugefärbter Alkaliverbindung eine wasserreichere Säure zugrunde liegt. In

${ }^{1}$ H. W. Voger, Praktische Spektralanalyse 1889 I, S. 375. 
den verdünnten, durch das Licht zum Teil gebleichten Jodeosinlösuungen ist von einer Blaufärbung nichts zu bemerken; sie zeigen vielmehr einen gelbroten Farbenton, während sie ursprünglich rosenrot waren. Inwieweit bei dieser Farbenänderung Oxy. dationsprozesse mitwirken mögen, soll hier nicht erörtert werden.

Die oben beschriebenen Versuche haben ergeben, dafs zur einwandfreien Aufbewahrung alkalischer Eosinlösungen die käuflichen braungelben Flaschen nicht genügen.

Der Bleichvorgang wird vermutlich zumeist durch die von dem Farbstoff absorbierbaren grünen Lichtstrahlen herbeigeführt, und diese gehen, wie ein Blick in das Spektroskop ergibt, durch das braune Glas hindurch.

Es bedarf vielmehr zur Aufbewahrung der Lösungen der völligen Fernhaltung des Lichtes, also schwarzer Flaschen, welche gegenwärtig kaum noch käuflich sind. Sie wurden vor 30 Jahren, als man die chemischen Lichtwirkungen meist auf ultraviolette Strahlen zurückführte, durch die braunen Flaschen aus dem Handel verdrängt. ${ }^{1}$ Die lichtschützende Wirkung dieser letzteren wird aber augenscheinlich vielfach überschätzt, und die Wiedereinführung der schwarzen Flaschen mufs im Interesse der Technik aufs neue gefordert werden.

Als eine vorrätig zu haltende alkalische Eosinlösung, welche zur Herstellung verdünnter Lösungen für den Gebrauch dienen kann, empfiehlt sich die Lösung 1:1000, welche aus $1 \mathrm{~g}$ Jodeosin und $24 \mathrm{ccm} 1 / 10^{-n o r m}$. Natronlauge durch Auffüllen mit Wasser zum Liter leicht herzustellen ist.

Aber auch diese Flüssigkeit bedarf, wie die Normallösungen der Malsanalyse, von Zeit zu Zeit einer Kontrolle.

\section{Die Bruchflächen.}

Unregelmärsige Bruchstücke von Glas sind für den vorliegenden Zweck wenig geeignet, da sie nur selten glatte und melsbare Oberflächen aufweisen. Ein Zerschlagen kompakter Glasstücke mit dem Hammer gibt nur eine geringe Ausbeute brauchbarer Stücke.

Zur Gewinnung einwandfreier Bruchflächen dienen am besten scharfkantige Glasstreifen von $4-8 \mathrm{~mm}$ Dicke und $2-4 \mathrm{~cm}$ Breite, welche aus gröfseren Tafeln glasermärsig leicht abzuschneiden sind.

1 Die Firma Warmbrunn Quilitz \& Co. hat gemäls privater Mitteilung ihren grofisen übriggebliebenen Vorrat von schwarzen Flaschen durch Einschmelzen seinerzeit vernichtet. 
Bei dem Querbruch solcher Glasstreifen ist das Ritzen mit dem Diamanten zu vermeiden, da der so angebahnte Bruch zu mehr oder weniger rauhen Flächen führt. Mindestens ist die durch das Ritzen entstandene Kante rauh und gibt zu Störungen Veranlassung.

Glatte Bruchflächen erzielt man, indem man den Bruch von einem Kerb ausgehen lälst, welchen man mit Hilfe einer gröberen dreikantigen Feile an einer scharfen Kante des Glasstreifens erzeugt.

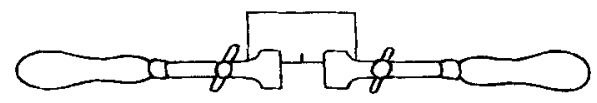

Fig. 3.

Spannt man jetzt die Platte in der beigezeichneten Weise in zwei mit Kork ausgelegte Feilkloben und übt auf die Handhaben einen sanften Druck aus, so erfolgt der Bruch mit grofser Leichtigkeit und führt stets zu glatten, leicht melsbaren Flächen. Das Brechen geht bier vom scharfen Kerb aus als eine regelmälsige Spaltung vor sich. Ist zum Bruch ein grölserer Kraftaufwand nötig, so ist dies ein Zeichen gewaltsamen Zerreifsens an nicht beabsichtigter Stelle; hierbei entstehen rauhe Flächen.

Bruchflächen von 100-200 qmm sind für die Versuche am bequemsten. Die Auswertung der Fläche erfolgt mit Dickenmesser und Millimeterstab; dabei sind Fehler von $\pm 2 \%$ zuzulassen. Der stets rauhe dreieckige Kerbabschnitt, welcher kaum $1 \%$ der Fläche ausmacht, ist nicht mitzurechnen.

Unregelmälsigkeiten der Kanten oder Krümmungen der Flächen wird man zweckmäfsiger durch Schätzung berücksichtigen als durch mühsame Messungen genau auswerten.

Häufig steht die Glasmasse nicht in dicken Tafeln, sondern nur in mehr oder weniger dünnen, oft gekrümmten Lamellen zur Verfügung, wie in Röhren, Flaschen, Kolben usw. In diesen Fällen mufs man sich mit einer geringeren Genauigkeit bei der Messung der Bruchflächen und bei dem Ergebnis der Versuche begnügen. Biegeröhren und Glasstäbe von erheblicher Dicke liefern häufig rauhe Bruchflächen.

Das Bestreben, jede vorliegende Glasprobe vor der Lampe in eine für den Bruch geeignete Gestalt zu bringen (etwa eine rechteckige Platte), hat zu keinem befriedigenden Ergebnis geführt. Verdampfen von Alkali und Entglasungserscheinungen verursachen hier mannigfache Störungen. Die Verarbeitung zu dünnen Stäben ist 
noch am leichtesten erreichbar; die Bruchflächen derselben sind aber für genauere quantitative Bestimmungen zu klein.

\section{Der Beizvorgang.}

Nachdem der Bruch in der soeben beschriebenen Weise vollzogen worden ist, stäubt man die Bruchfläche mit einem Tuschpinsel schnell $a b$ und taucht das Bruchstück des zu prüfenden Glases mit Hilfe einer vergoldeten Pinzette schnell in der ätherischen Eosinlösung unter.

In den meisten Fällen soll die Berührung mit dem Reagens nur 1 Minute dauern. Hierzu ist ein kleiner Präparatenzylinder mit gutschliefsendem Stöpsel zweckmälsig, welcher unmittelbar vor dem Gebrauch mit dem empfindlichen Reagens zu drei Viertel gefüllt wurde; in ein ähnliches Gefäls giefst man den zum Abspülen dienenden, mit Soda behandelten Äther.

Nach Ablauf der Reaktionsfrist zieht man das Glasstück schnell aus der Eosinlösung und führt es in den Spüläther über, was leicht innerhalb ron zwei Sekunden geschehen kann. Ein mehrmaliges Hin- und Herführen in der Flüssigkeit entfernt das anhaftende Reagens; nunmehr wird das gebeizte Bruckstück schnell nach gutem. Ablaufe des Äthers auf eine Lage Filtrierpapier gelegt, worauf alsbald ein völliges Trocknen erfolgt. In keinem Falle darf es während der Verdunstung des Äthers zu einem Niederschlagen von Wasser kommen. Dies würde eine Tropfenbildung und somit eine Inhomogenität der gefärbten Schicht bedeuten, welche zu erheblichen Störungen führt.

Die Bruchfläche ist jetzt mit einer gleichmäfsigen roten Schicht überzogen, welche im auffallenden Licht glänzend grün erscheint; aber auch die übrigen Teile des Glasstückes sind gewöhnlich ein wenig gefärbt.

Es ist daher notwendig, die nicht in Betracht kommenden Oberflächen mit einem angefeuchteten Tuche vom Farbstoff zu säubern; besonders sorgfältig mufs dies mit der rauhen Ecke geschehen, welche von dem durch Feilen erzeugten Kerbe herrührt, denn an dieser Stelle liegen besonders grofse Mengen von Farbstoff angehäuft.

Der Beizrorgang darf übrigens in dem mit Luft gefüllten Gefäls nur vorgenommen werden, wenn die Reaktionszeit wenige Minuten beträgt.

Bei einer Stundenprobe ist es nötig, das Gefäls soweit mit dem Reagens zu füllen, dafs der eingesetzte Glasstöpsel jede Spur von Luft verdrängt, der Cylinder also völlig mit Flüssigkeit angefüllt ist. 
Bei Dauerversuchen bei einer Berührungszeit von einem oder mehreren Tagen genügt auch diese Anordnung nicht, denn trotz des Glasstöpselverschlusses würde Äther verdunsten und Luft in das Gefäls eindringen, wodurch die Empfindlichkeit der Reaktion beeinträchtigt wird.

Für solche Fälle haben sich Zylinder mit aufgestülptem Rand zweckmälsig erwiesen; wie Fig. 4 zeigt, besitzen sie oberhalb des Stöpsels einen Raum, welcher mit einer $1 \%$ igen Lösung ron eosinsaurem Natrium gefüllt werden kann. Hierdurch ist der $\mathrm{Zu}$ tritt von Luft verhindert, und es findet an der Schlifftläche des Stöpsels nur ein Austausch von Äther durch wässerige Eosinlösung statt.

Zum Innehalten der Temperatur von $18^{\circ}$ während längerer Zeit bedarf es eines Ther. mostaten.

Nicht immer lassen sich kleine Temperaturschwankungen vermeiden; eine Erhöhung der Temperatur hebt die Sättigung des

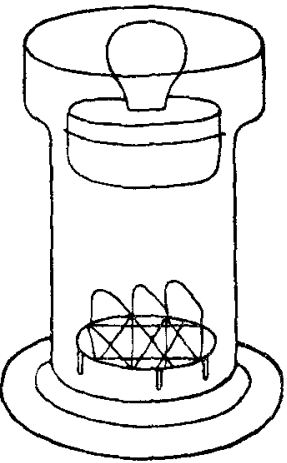

Fig. 4. ätherischen Reagens für Wasser auf und verändert durch einen Trockenprozels die niedergeschlagene Farbstoffschicht; sie kann dadurch in Wasser unlöslich werden.

Eine Erniedrigung der Temperatur führt Übersättigung mit Wasser herbei und kann unerwünschte Tropfenbildung an der Bruchfläche verursachen.

Praktisch hat es sich bei Dauerversuchen bewährt, in das Reaktionsgefäis neben der ätherischen Lösung noch einige Tropfen derselben wässerigen Eosin-Natriumlösung einzuführen, welche den Glasstöpsel abschliefst. Das Reagens wird dadurch mit Wasser gesättigt gehalten, und der Bildung fremder Säuren ist zugleich vorgebeugt.

Bei der gleichzeitigen Prüfung mehrerer Glasstücke dient ein kleiner Einsatzkorb aus Platindraht zur Aufnahme derselben (Fig. 4). Unedle Metalle haben sich dazu nicht bewährt. Messing, Nickel, Kupfer, Zinn, selbst Silber überziehen sich dabei mit den roten Metallsalzen des Jodeosins, was sich aus der aktiven Beschaffenheit des im Äther gelösten Sauerstoffs erklärt.

Die auf der Bruchfläche abgelagerte Farbstoffschicht lälst sich entweder durch Abdruck oder durch Auflösen in Wasser kolorimetrisch verwerten. 


\section{Farbenabdruck der Beizschicht.}

Die grünschillernde, auf der Bruchfäche lagernde Farbschicht läfst sich ihrem Betrage nach nicht abschätzen, solange sie am Glase haftet. Man ist jedoch leicht imstande, den Farbstoff nach Art des Stempelns auf weifses Papier zu übertragen. $\mathrm{Zu}$ diesem Zweck wird ein gehärtetes Filter von Schleicher \& Schüll mit Wasser getränkt auf eine mit trockenem Filtrierpapier bedeckte Kautschukplatte gelegt. Bei der Abstempelung auf diesem feuchten Polster erhält man scharf begrenzte rote Bilder der Bruchflächen, deren wechselnde Farbenintensität die Reaktionsfähigkeit verschiedener Gläser objektiv zum Ausdruck bringt.

Bereits oben wurde angedeutet, dals Konzentrationsänderungen im Gehalt des ätherischen Reagens an Jodeosin für die Menge des niedergeschlagenen Farbstoffes kaum von Einflufs sind; die Menge ist merklich gleich, ob die Lösung $1 \mathrm{~g}$ oder 0.2 Gramm Jodeosin im Liter enthält, da der Überschufs der Säure über das zu bindende Alkali in beiden Fällen sehr grofs ist.

Morphologisch ist jedoch ein Unterschied deutlich wahrzunehmen. Im ersteren Fall ist die niedergeschlagene Schicht von eosinsaurem Alkali homogen und amorph; sie erteilt dem Glase bei der Durchsicht eine rote Färbung; im letzteren Fall, wo in der verdünnteren Lösung die Sättigung des Alkali mit Eosin langsamer geschieht, ist das niedergeschlagene Salz krystallisiert und macht sich nur durch eine leichte rötliche Trübung bemerkbar, welche sich unter dem Mikroskop in körnige Formelemente auflöst. Die Bruchfläche erscheint in diesem Falle bei der Durchsicht ebensowenig rot, wie im reflektierten Lichte grün.

Wird aber auf dem erwähnten Wege eine Abstempelung vorgenommen, so erscheint die Rotfärbung auf dem Papier in beiden Fällen gleich intensiv; wie leicht ersichtlich, wird auf dem feuchten Papier eine gleich konzentrierte Lösung des Farbstoffes erzeugt.

Bei der Prüfung sehr alkalireicher Gläser kann auch die konzentrierte ätherische Eosinlösung eine Trübung des niedergeschlagenen Farbstoffes durch Krystallisation bei längerer Berührungszeit herbeiführen; die direkte Vergleichung mehrerer gebeizter Glasstücke durch den Augenschein wird dadurch bedeutend erschwert; das Abdruckverfahren hebt diese Schwierigkeit auf; es genügt indessen ebenfalls nicht strengeren Anforderungen der Unterscheidung. Bei geringer Farbenintensität treten die Unterschiede 
viel deutlicher hervor als bei hoher Intensität, wo die Schicht des ziegelroten Eosinsalzes beinahe wie eine „Deckfarbe“ wirkt. Aufserdem wird die Färbung des Abdruckes wesentlich durch die verschiedene Dicke und den Wassergehalt des Papiers, den angewandten Druck usw. beeinflufst. Aus diesen Grüıden würde auch die Aufstellung einer bestimmten Farbenskala zur Beurteilung der Glasmassen nach dieser bequemen Probe keinen Zweck haben.

\section{Die kolorimetrische Bestimmung auf nassem Wege.}

Der auf der Bruchfläche niedergeschlagene Farbstoff ist in wässeriger Lösung bestimmt durch diejenige (rewichtsmenge krystallisierten Jodeosins, welche in dem gleichen Volumen alkalischen Wassers den gleichen Farbeneffekt hervorruft.

Die zur Vermittelung der Vergleichung dienende alkalische Lösung enthält $0.01 \mathrm{mg}$ Jodeosin in einem Kubikzentimeter.

Die in der analytischen Praxis gebräuchlichen Kolorimeter ${ }^{1}$ (welche die Versuchsfehler bis auf $0.5 \%$ des Wertes herabzudrücken erlauben) sind für den vorliegenden $Z$ weck nicht geeignet, da sie auf gröfsere Flüssigkeitsmengen und auf durchfallendes Licht berechnet sind. Hier handelt es sich aber um kleine Volumina Lösung von so geringer Farbenintensität, dafs zur besseren Beleuchtung des Farbstoffes die Reflexion von weifsen Wänden zu Hilfe genommen werden muls. Bei meinen Versuchen bediene ich mich einer sehr einfachen Vorrichtung, welche Intensitätsunterschiede von $5 \%$ noch leicht zu erkennen erlaubt und sich bis jetzt bewährt hat. Dieselbe besteht, wie Fig. 5 zeigt, aus einem kegelförmigen, in zwei gleiche Kammern geteilten Gefäls aus weifs lackiertem Messingblech, welches drehbar auf einer senkrechten Achse befestigt ist.

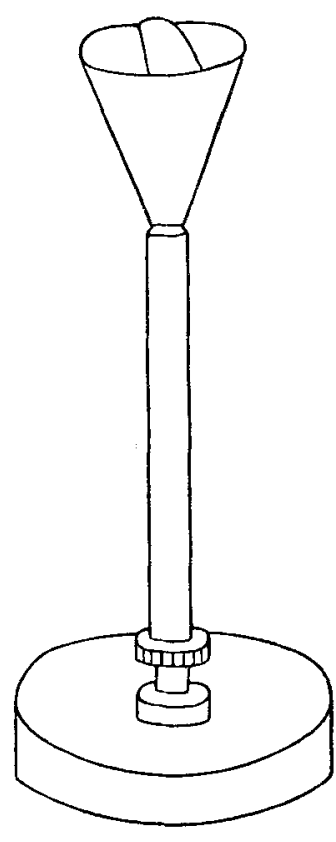

Fig. 5.

In welcher Weise dieser Doppeltrichter aus einer runden Messingscheibe durch Verlöten herzustellen ist, mag Fig. 6 andeuten.

1 Vergl. G. u. H. Knüss, Kolorimetrie 1891, S. 43.

Z. suorg. Chem. Bd. 5ó. 
Zweckmäfsig werden mehrere solche Trichter von verschiedenem Inhalt $(5,10,50 \mathrm{ccm})$ vorrätig gehalten, welche nach Erfordernis auf dem Stativ auszuwechseln sind.

Behufs der kolorimetrischen Bestimmung fafst man das gebeizte, sauber gereinigte Glasstück mit der Pinzette und spült die Bruchfläche durch häufig wiederholtes Eintauchen in $2-3 \mathrm{ccm}$ alkalischem Wasser ab, welche sich in einem flachen Uhrglase befinden.

Die rote Lösung wird nunmehr in die eine Kammer des Kolorimetertrichters gegossen und durch eine erneute Abspülung der Bruchfläche ergänzt. Als Gefärs für das nötige alkalihaltige

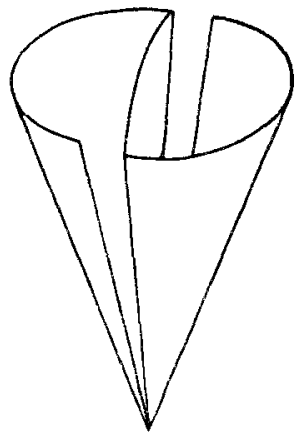

Fig. 6.

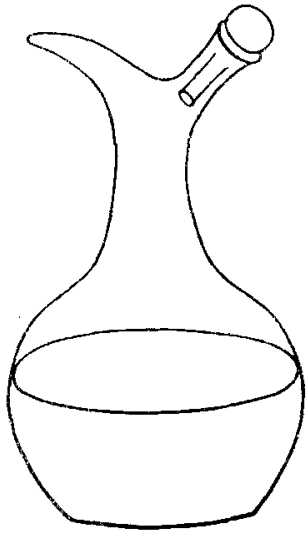

Fig. 7.

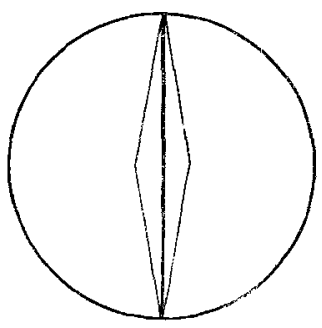

Fig. 8.

Wasser dient dabei zweckmälsig ein Tropfkolben von der in Fig. 7 angedeuteten Form. Unter Zusatz von Wasser lälst man nun aus einer mit der Hand gehaltenen graduierten Capillarpipette soviel der roten Vergleichslösung in die zweite Trichterkammer einfliefsen, dafs bei gleichem Flüssigkeitsniveau der Augenschein in beiden Kammern gleiche Farbenintensität ergibt; das Urteil darüber wird durch eine Drehung des Trichters behufs der Vertauschung der Felder ungemein erleichtert. In dem Doppeltrichter, welcher an der Spitze einen Winkel von $30-45^{\circ}$ haben mag, können kleinere oder gröisere Flüssigkeitsmengen unter analogen Bedingungen für den Vergleich voll ausgenutzt werden.

Der Vergleich der Färbungen wird nicht wesentlich durch die Abtönung der verschiedenen Schichtendicke, und ebensowenig durch die in Fig. 8 angedeutete Refraktionserscheinung gestört. Diese besteht darin, dals innerhalb der Flüssigkeit beide Flächen der 'Trichterscheidewand dem darüber befindlichen Auge sichtbar werden, 
wobei die Spitzen beider Trichterkammern durch eine rautenförmige Unterbrechung getrennt erscheinen.

Die senkrechte Betrachtung zeigt bei gleichförmiger Beleuchtung ein Bild, welches in beiden Hälften eine völlige Symmetrie nach Form und Farbe aufweist.

\section{B. Ergebnis der Eosinprobe bei verschiedenen Glasarten.}

So einfach auch das Prinzip der Eosinprobe erscheint, bedarf ibre Handhabung doch eine erhebliche Vorsicht, wenn sie zu sicheren Ergebnissen führen soll.

Die im Abschnitt A erörterten Fehlerquellen sind in der Tat so bedeutend, dafs die Frage berechtigt ist, ob dem Verfahren in der angegebenen Form überhaupt ein analytischer oder technischer Wert zukommt.

Es hat sich nämlich herausgestellt, dafs man kaum noch auf eine sichere zahlenmälsige Vergleichung zweier Glasarten rechnen kann, wenn sie hinsichtlich der Reaktionsfähigkeit um $10 \%$ voneinander verschieden sind.

Eine Orientierung über das spezielle Verhalten der in der Technik verwendeten Glasarten wird am besten geeignet sein, die Frage zu beantworten.

\section{Versuche mit Spiegelglas unter wechselnden Bedingungen.}

Verwendet wurden geschliffene Platten des rheini schen Spiegelglases von $6 \mathrm{~mm}$ Dicke. Die vielfache Verwendnng zu Spiegelscheiben garantiert eine gewisse Haltbarkeit gegen Verwitterungseinflüsse.

Die gebeizten Bruchflächen betrugen zwischen 100 und $200 \mathrm{qmm}$, und die darauf niedergeschlagene Menge Jodeosin wenige 1000 stel Milligramm.

Zu jedem Versuch wurde ein frisches Bruchstück benutzt.

(S. Tabelle, S. 252.)

In der nachstehenden Zusammenstellung sind die verschiedensten Eosinwerte vertreten. Die Versuche Nr. 2, 3 und 4 ergeben Beispiele der Schwankungen, welche gleichartige Bestimmungen ergeben können; es empfiehlt sich, das Mittel aus mehreren Bestimmungen zu bilden und die auf $100 \mathrm{qcm}$. Oberfäche bezogenen Eosinwerte in Milligrammen bis auf zwei Dezimalen abzurunden. Die Versuche 
$1 \mathrm{ccm}$ der Vergleichslösung $=0.01 \mathrm{mg}$ Jodeosin.

\begin{tabular}{|c|c|c|c|c|c|}
\hline $\begin{array}{l}\text { Ver- } \\
\text { suchs- } \\
\text { Nr. }\end{array}$ & $\begin{array}{c}\text { Brucbstücke } \\
\text { vor dem Beizen }\end{array}$ & $\begin{array}{l}\text { Ein- } \\
\text { taueh- } \\
\text { zeit }\end{array}$ & $\begin{array}{l}\text { qmm } \\
\text { Bruch- } \\
\text { fläche }\end{array}$ & $\begin{array}{l}\text { ecm } \\
\text { Vergleichs- } \\
\text { lösung }\end{array}$ & $\begin{array}{l}\mathrm{mg} \text { Jod- } \\
\text { eosin auf } \\
100 \mathrm{qcm}\end{array}$ \\
\hline 1 & sogleich gebeizt & 1 Sekund. & 180 & 0.28 & 0.155 \\
\hline 2 & $\eta$ & 1 Minute & 180 & 0.35 & 0.194 \\
\hline 3 & $n$ & $1 \quad$, & 180 & 0.34 & 0.189 \\
\hline 4 & $n$ & $1 " n$ & 180 & 0.37 & 0.205 \\
\hline 5 & $"$ & 1 Stunde & 180 & 0.38 & 0.21 \\
\hline 6 & $\because$ & $1 \mathrm{Tag}$ & 180 & 0.50 & 0.28 \\
\hline 7 & $\begin{array}{l}15 \text { Minuten } \\
\text { zwischen Uhrgläsern }\end{array}$ & 1 Minute & & & 0.195 \\
\hline 8 & $\begin{array}{c}15 \text { Minuten } \\
\text { Laborator.-I } \mathrm{fuft}\end{array}$ & $1 \%$ & & & 0.145 \\
\hline 9 & $\begin{array}{l}1 \text { Stunde } \\
\text { Laborator.-Luft }\end{array}$ & $1 \%$ & & & 0.07 \\
\hline 10 & $\begin{array}{c}24 \text { Stunden } \\
\text { Laborator.-Luft }\end{array}$ & $1 "$ & & & 0 \\
\hline 11 & $\begin{array}{l}\text { Abspülen mit Alko- } \\
\text { hol, dann mit Äther }\end{array}$ & 1 & $\begin{array}{l}380 \\
2 \text { Stücke }\end{array}$ & 0.8 & 0.21 \\
\hline 12 & $\begin{array}{l}\text { Abspülen mit Wass., } \\
\text { dann mit Alkohol } \\
\text { und mit Ather }\end{array}$ & 1 & $\begin{array}{l}300 \\
2 \text { Stücke }\end{array}$ & 0.25 & 0.03 \\
\hline 13 & $\begin{array}{l}10 \text { Min. in Wasser. } \\
\text { Abspülen mit Alko- } \\
\text { hol und mit Äther }\end{array}$ & 1 & 180 & 0 & 0 \\
\hline
\end{tabular}

7-10 zeigen, dafs die gewöhnlich saure Luft eines Laboratoriums auf die frische Bruchfläche eines Glasstückes sogleich neutralisierend einwirkt in dem Grade, dafs dieser Einflufs binnen einer Stunde den Effekt der Eosinprobe zu zwei Drittel vernichtet.

Die Eosinprobe mufs daher in gut ventilierten Räumen vorgenommen werden; die wenigen Sekunden, welche zwischen dem Zerbrechen des Glases und der Benetzung mit dem flüssigen Reagens vergehen, können dann in ihrem Einflufs vernachlässigt werden.

Vergleicht man Nr. 1 und 6, so findet man, dal's eine 24 stündige Berührung mit dem Reagens noch nicht doppelt soviel Farbstoff auf der Bruchfläche niedergeschlagen hat als die Einwirkung während einer Sekunde.

Man erkennt zunächst daran, dafs die Sättigung des angezeigten Alkalis mit der im Reagens befindlichen Eosinsäure so schnell vor sich geht, wie man es von einer Ionenreaktion erwarten kann. Dann aber ferner, dafs auch die erste Phase der Reaktion, 
die hydrolytische Bildung von Alkali aus dem unveränderten Glase zunächst nur kleine Zeiträume beansprucht. Verglichen mit der Indifferenz der geschliffenen Glasflächen gegen die Aufnahme des Eosins erscheint der Anfangswert bei der Bruchfläche überraschend grofs. Hier bewirkt aber die zunehmende Dauer der Hydrolyse sehr bald eine Art Passivität der Glassubstanz, indem sich dieselbe mehr und mehr mit einer schwer durchdringlichen Silicatschicht überzieht, und diese Wirkung ist bereits nach 1 Minute wahrnehmbar.

Der Versuch 11 bestätigt die bekannte Tatsache, dafs die Glassubstanz das Alkali nicht als freies Oxyd enthält; Alkohol würde es sonst in Lösung bringen.

Die Versuche 12 und 13 zeigen andererseits, dafs das anfangs hydrolytisch erzeugte Alkali durch flüssiges Wasser schon nach wenigen Minuten von der Oberfläche völlig entfernt wird.

Die Minuten-Eosinprobe hat bei dem rheinischen Spiegelglas also $\mathrm{zu}$ dem konstanten Wert 0.2 Milligramm Jodeosin auf das Quadratdezimeter geführt, welcher $0.02 \mathrm{mg} \mathrm{NaHO}$ äquivalent ist.

Man vermag aus dem nach einer Minute angezeigten Alkali jedoch nicht den Betrag der durch das Wasser zersetzten Glasmasse zu berechnen, da vermutlich nicht die ganze Menge des in dieser ursprünglich vorhandenen Natrium- oder Kaliumoxyds in den gefärbten Niederschlag übergeht; ein Teil davon bleibt vielmehr in der nunmehr wasserhaltigen kieselsäurereicheren Oberflächenschicht zurïck und entzieht sich der kolorimetrischen Wahrnehmung.

Angenommen, dieser T'eil betrage zehnmal so viel als der durch den Beizvorgang angezeigte Teil des Alkalis, so würde, entsprechend $2 \mathrm{mg}$ Jodeosin, das Gesamtalkali in der zersetzten Glasschicht noch nicht $0.2 \mathrm{mg}$ Natriumoxyd gleichwertig sein. Wie die Zusammensetzung des Glases ergibt, hätte sich also die hydrolytische Veränderung vollzogen an etwa $1.5 \mathrm{mg}$ oder $0.6 \mathrm{cmm}$ einer Glasmasse, welche sich auf $100 \mathrm{qcm}$ Oberfläche verteilt. Daraus berechnet sich eine Schichtendicke derselben von $0.00006 \mathrm{~mm}$.

Mag auch diese Schätzung um den zehnfachen Betrag zu niedrig sein, so ist es in jedem Falle bemerkenswert, dafs eine Silicatschicht von dieser Gröfsenordnung die darunter befindliche Glasmasse gegen die rasche Zersetzung durch das Wasser deutlich zu schützen vermag. 


\section{Wasserglas.}

Als Typus der schlechtesten Gläser andererseits kann das technische Wasserglas gelten, dem sich die „minderwertigen Gläser“ der Technik in Zusammensetzung und Eigenschaften mehr oder weniger nähern.

Die hydrolytische Untersuchung der Alkalisilicate von der einfachsten Zusammensetzung würde wissenschaftlich am interessantesten sein, sie ist jedoch schwer durchzuführen; gewöhnlich steht nur das technische Natron- oder Kaliwasserglas in geschmolzenen klaren Massen zur Verfügung, welche ca. $1 \%$ erdige Stoffe enthalten.

Ich habe mit dem technischen Natronwasserglase einige orientierende Versuche über die Eosinprobe ausgeführt, welche folgendes ergeben haben.

Bei einer Eintauchzeit von einer Minute erhält man hier auf $100 \mathrm{qcm}$ Bruchfläche $6 \mathrm{mg}$ Jodeosin, bei einer Einwirkung von 24 Stunden etwa $200 \mathrm{mg}$, mithin $33 \mathrm{mal}$ soviel; das Spiegelglas hatte dagegen 0.2 und $0.28 \mathrm{mg}$ des Farbstoffes ergeben; hier war das Verhältnis nur $1: 1.4$.

Zur Charakterisierung des Spiegelglases durch die Eosinprobe genügte schon eine Minute Eintauchzeit. Das technische Wasserglas hatte bei analoger Prüfung einen $30 \mathrm{mal}$ so grofsen Wert ergeben.

Mithin ist Aussicht vorhanden, dafs man auch bei anderen besseren oder intermediären Glasarten mit der kurzen Reaktionszeit von einer Minute merkliche Unterschiede wird feststellen können.

\section{Eosinwerte bei anderen Glasarten. \\ Minutenprobe.}

Die Prüfung verschiedenartiger Glasarten mit Hilfe der ,Minutenprobe" hat für $100 \mathrm{qcm}$ der Bruchfläche folgende bereits 1904 erhaltene Werte ${ }^{1}$ ergeben:

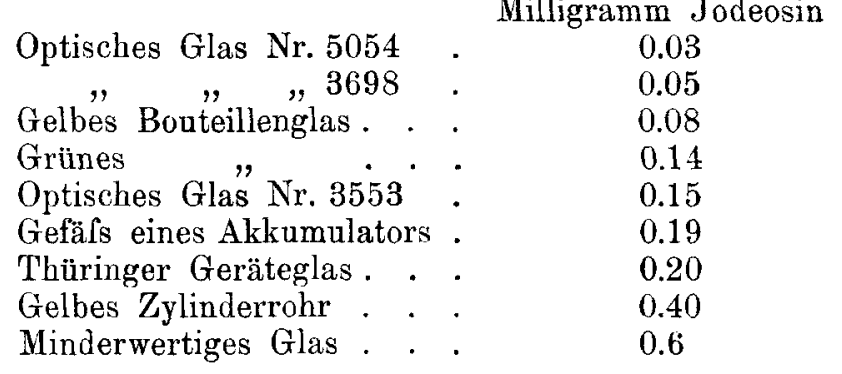

${ }^{2}$ Die Tätigkeit d. Phys.-Techn. Reichsanstalt 1904; Zeitschr. f. Instrumentenk. 1905, 149. 
Man ersieht aus dieser Zusammenstellung, dafs das hydrolytische Verhalten der in der Technik verarbeiteten Glassorten erheblich verschieden ist, und dafs die Eosionprobe trotz ihrer Fehlerquellen ein Mittel darstellt, die Glasarten nach dem Grade ibrer chemischen Aktivität in überraschend kurzer Zeit zu kennzeichnen.

Die so erhaltenen Eosinwerte, bezogen auf die Oberfiächeneinheit, sind etwa dem zehnten Teil ihres Gewichtes Natron äquivalent; eine entsprechende Menge von Alkali war hydrolytisch bei dem Beizvorgang aus dem Glase erzeugt worden.

Man kann diesen Vorgang in feuchtem Äther am ehesten dem hygroskopischen Verhalten der Gläser in feuchter Luft an die Seite stellen; deutlicher erscheint der Parallelismus noch im Vergleich mit der "Verwitterung".

Hier wie dort ist es das Wasser, welches zunächst auf das Glas zersetzend einwirkt, indem es Alkali erzeugt. Während dasselbe bei dem Beizvorgang sogleich an die Eosinsäure gebunden wird, ist es bei der Verwitterung die Kohlensäure, welche es sogleich in Beschlag nimmt. In der 'Tat bestehen bekanntlich die auf dem Glase sich ansammelnden Verwitterungsprodukte zum weitaus grölsten Teil aus Alkalicarbonat.

\section{Optische Gläser.}

Wenn es im ganzen schon ein erheblicher Vorteil ist, die zu den verschiedensten Zwecken der Technik benutzten Glasarten miteinander hydrolytisch vergleichen zu können, so könnte ein solches Verfahren den für die Optik gebrauchten Glasarten besonders zugute kommen. Hier spielen die alkalischen Verwitterungsprodukte, welche sich auf den geschliffenen Objekten ablagern, eine äufserst störende Rolle, and es gab bisher keine zuverlässige Methode, welche den Grad der Verwitterbarkeit eines optischen Glases im voraus zahlenmälsig zu bestimmen erlaubt. Man war hier vielmehr auf die sorgfältige Beobachtung der zunehmenden Trübung angewiesen, welche die Atmosphäre in langen Zeiträumen auf den polierten Glasstücken tatsächlich hervoruft. Erst in neuester Zeit ist von Herrn E. ZCBIMMER ${ }^{1}$ eine auf der Wirkung erwärmter feuchter Luft beruhende wirksame Methode ermittelt worden, solche Verwitterungserscheinungen auf mikroskopischem Wege in verhältnismälsig kurzer Zeit zu erkennen.

1 E. Zschimmer, Z. f. Elehtrachem. 11 (1905), 629. 
Seitdem die Herstellung optischer Glasarten durch das wissenschaftliche Zusammenwirken von ABвE und Sснотт eine so grolse Förderung erfahren hat, ist das Bedürfnis der Beurteilung des Glases nach ehemischer wie nach physikalischer Richtung in fort. gesetztem Steigen begriffen.

Die Firma Schott und Gen. in Jena hat der Reichsanstalt Platten von 17 verschiedenen Typen optischer Kron- und BorosilicatKrongläser zur Verfügung gestellt, an denen das Eosinverfahren versucht worden ist.

Diese Platten waren mit der Diamantsäge aus gröfseren Stücken geschnitten, aber nicht poliert worden. Das Eosinverfahren ist dadurch besonders erschwert, denn in den rauhen Oberflächenschichten der Glasstücke lagert sich besonders viel Farbstoff ab, welcher vor der kolorimetrischen Auswertung der glatten Bruchfläche nur mit der gröfsten llühe entfernt werden kann.

Trotz dieser Erschwerung gelang es bei Anwendung der Minutenprobe leicht, das haltbarste Glas zu ermitteln. Vor den Versuchen hatte ich die Kenntnisnahme der Bezeichnung oder der Zusammensetzung der Glastypen absichtlich vermieden.

Herr Dr. Zsснгмmer in Jena, mit welchem ich in Verbindung getreten bin, hat andererseits Parallelversuche ausgeführt, bei welchen nicht Bruchstücke, sondern geschliffene und polierte Proben der 17 Glasarten in Dauerversuchen auf die bei der natürlichen Verwitterung entstehenden Beschläge geprüft wurden.

Die Glasproben, runde Scheiben von $10 \mathrm{~mm}$ Durchmesser, waren unterhalb der plangeschliffenen Deckplatte eines mit gewöhnlicher atmosphärischer Luft gefüllten, hermetisch abgeschlossenen Glastroges (von halbzylindrischer Form, $160 \mathrm{~mm}$ Länge und $35 \mathrm{~mm}$ Durchmesser) reihenweise befestigt; sie waren also dauernd mit ca. $60 \mathrm{ccm}$ Luft von gewöhnlichem Wasser- und Kohlensäuregehalt in Berührung, und ihre Veränderung konnte mikroskopisch verfolgt werden. ${ }^{1}$

Die Figg. 1-4 Tafel VI zeigen bei 4 verschiedenen Glastypen die im Laufe von 8 Monaten entstandenen Verwitterungsprodukte als feine Tropfenbildungen bei 56 facher Vergröfserung. ${ }^{2}$

Die Eosinprobe an Bruchflächen derselben Glasarten ergab

${ }^{1}$ Zur Dichtung wurde Mastixkitt verwendet; es ist daher nicht ausgeschlossen, dafs die Luft eine Spur flüchtiger Harzbestandteile enthielt.

${ }^{2}$ Nur das Kronglas 0.60 (Nr. 4) war über 1 Jahr der Luft ausgresetzt gewesen; schon nach 8 Monaten schien die Tropfenbildung gleich intensiv. 
andererseits (bei einer Eintauchzeit von 1 Stunde) auf 1 qdem der Bruchfläche für:

1. Jenaer Borosilicatkron 0802 . . $0.01 \mathrm{mg}$ Jodeosin

2. " Prismenkron 03832 . . 0.02 , ,

3. " Borosilicatkron 03453 . . 0.15 ,, ,

4. " Silicatkron 060 . . . . 0.4 , ,

Die Veränderung der Gläser hat sich also bei beiden Versuchsreihen in der gleichen Reihenfolge vollzogen.

An die Haltbarkeit des Glases 2 Typus 03832 werden in der optischen Praxis die grölsten Anforderungen gestellt; es wird für Feldstecherprismen, Entfernungsmesser usw. in abgeschlossenen Räumen verwendet, welche eine Reinigung der Glasflächen nicht gestatten. Erfahrungsgemäfs ist ein Glas dieser Art für die genannten $\mathrm{Zwecke}$ vorzüglich geeignet.

Noch etwas widerstandsfähiger hat sich das Glas 1 erwiesen.

Andererseits kommen bei den Gläsern 3 und 4 die Einflüsse der Verwitterung in der Praxis schon wesentlich störend in Betracht.

Auch bei den übrigen Typen der 17 Glasarten machte sich (mit wenigen Ausnahmen) ein deutlicher Parallelismus in der Veränderlichkeit bei beiden Versuchsreihen bemerkbar.

Dadurch ist der Beweis erbracht, dals die an Bruchflächen der Gläser vorgenommene Eosinprobe auch zur Beurteilung der Verwitterbarkeit geschliffener Stücke geeignet ist. Ob die Eosinprobe einen Malsstab für die Haltbarkeit aller optischen Glastypen ergibt, bleibt noch zweifelhaft. Geltung hat die Probe zunächst nur für die gewöhnlichen Kron- und Borosilicatkrongläser. In welcher Beziehung die Eosinprobe zur Haltbarkeit der barytreichen schweren Krongläser und der bleireichen Flintgläser steht, mufs durch besondere Versuche festgestellt werden.

\section{Reaktionsfähigkeit des Glases nach Eosinkurven.}

Häufig wird der Fall eintreten, dals zwei Glasarten von wesentlich verschiedener Zusammensetzung bei einer kurzen Eintauchzeit den gleichen Eosinwert ergeben; eine längere Berührung mit der ätherischen Lösung schlägt dann mehr und mehr divergierende Mengen von Farbstoff nieder.

Zur eindeutigen Charakterisierung der Reaktionsfähigkeit einer Glasart ist demnach eine vereinzelte Eosinprobe bei be- 
stimmter Eintauchzeit nicht genügend; behufs genauerer Definierung mufs vielmehr auch die Zunahme der Eosinwerte bei wachsender Berührungszeit bestimmt werden.

Bei geringeren Glasarten wird man hier mit kurzen Zeiträumen auskommen, zum Beispiel:

\begin{tabular}{c|c|c|c|c|c}
\hline Nr. & \multicolumn{2}{|c|}{$\begin{array}{c}\text { Milligramme Jodeosin } \\
\text { 1 Minute }\end{array}$} & $\begin{array}{c}\text { Quotient } \\
\text { 1 Stunde }\end{array}$ \\
\hline 1 & Kanuten & 60 Min. & Minute \\
\hline 2 & Röhrenglas A (minderwertig) & 1.3 & 4.2 & 5.7 & 4.4 \\
3 & Röhrenglas B (minderwertig) & 0.5 & 1.0 & 1.5 & 3.0 \\
4 & Apparatenglas & 0.2 & 0.2 & 0.2 & 1
\end{tabular}

Während, wie die Kurvenzeichnung Fig. 9 ergibt, die Eosinwerte bei den minderwertigen Glassorten 1,2, 3 über eine Stunde hinaus stark zunehmen, ist das brauchbare Apparatenglas 4, ebenso wie das obenerwähnte Spiegelglas, bereits innerhalb einer Minute in den passiven Zustand gelangt. Um eine merkbare Zunahme der Eosinwerte festzustellen, würde es hier einer vielstündigen Eintauchzeit bedürfen.

Die resistenteren Glasarten liefern Eosinkurven, welche in ihrer Form nur wenig voneinander abweichen. Nachdem der hygroskopische Anfangseffekt schnell erreicht worden ist, tritt, wie bereits aben erwähnt, sehr bald ein Zustand langsamer Zersetzung ein, während dessen die anfangs stark gekrümmte Kurre fast geradlinig verläuft.

Dieser Teil der Kurve ist für die Beurteilung der Verwitterbarkeit des Glases in der Praxis malsgebend.

Anstatt der mühevollen Ermittelung einer vollständigen Kurve wird es bei deu technischen Gläsern in den meisten Fällen genügen, den Eosineffekt einer kurzen und einer langen Eintauchzeit zu ermitteln. Es empfiehlt sich demnach bei genaueren Untersuchungen, der Minutenprobe (I) eine Tagesprobe (II) an die Seite zu stellen, bei welcher die Eintauchzeit 24 Stunden dauert.

Der Wert I ist dann wesentlich als hygroskopischer Effekt, die Differenz II-I aber als die zeitliche Zunahme der Zersetzung zu betrachten, welche die langsame Verwitterung bestimmt.

Bei der Besprechung der optischen Gläser konnte die bekannte 


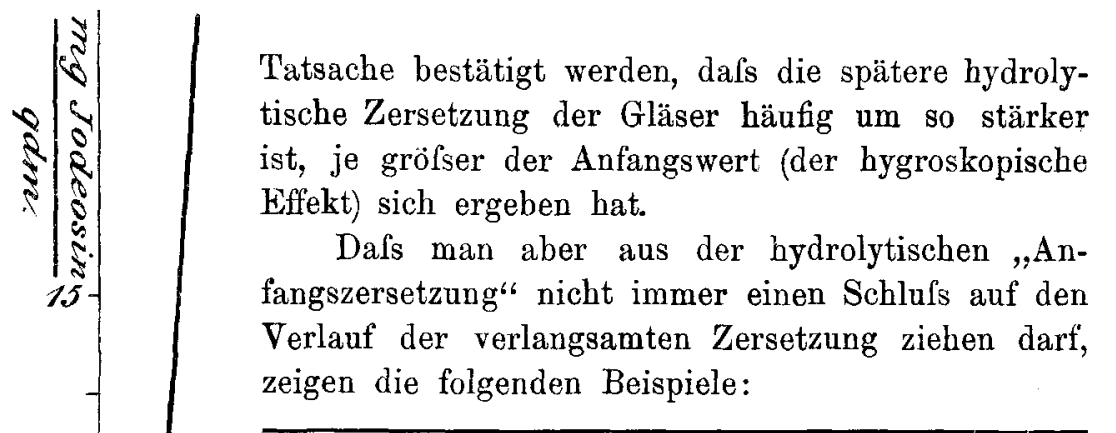

Tatsache bestatigt werden, dals die spatere hydrolytische Zersetzung der Gläser häufig um so stärker ist, je gröfser der Anfangswert (der hygroskopische Effekt) sich ergeben hat.

Dals man aber aus der hydrolytischen „,Anfangszersetzung" nicht immer einen Schlufs auf den Verlauf der verlangsamten Zersetzung ziehen darf', rigen die folgenden Beispiole:

\begin{tabular}{|c|c|c|c|}
\hline & \multicolumn{3}{|c|}{ Milligramme Jodeosion auf $1 \mathrm{qdm}$ Bruchfläche } \\
\hline & $\begin{array}{l}\text { Minuten- } \\
\text { probe I }\end{array}$ & $\begin{array}{l}\text { Tages- } \\
\text { probe II }\end{array}$ & $\begin{array}{c}\text { Zunahme } \\
\text { II-I }\end{array}$ \\
\hline Glas A & 0.01 & 0.01 & 0 \\
\hline,$\quad \mathrm{B}$ & 0.16 & 0.4 & 0.24 \\
\hline,$\quad \mathrm{C}$ & 0.17 & 0.8 & 0.63 \\
\hline, $\mathrm{D}$ & 0.20 & 1.1 & 0.9 \\
\hline Spiegelglas & 0.20 & 0.28 & 0.08 \\
\hline
\end{tabular}

Während bei den Glastypen $A B C$ und $D$ die „Zunahme“ mit den Anfangswerten I fortschreitet, ist sie bei dem Spiegelglase aufällig gering, besonders dem Glase $D$ gegenüber, mit welchem es den Anfangswert gemeinsam hat.

Die Zusammenstellung lälst erkennen, dafs man in der Spiegelglastechnik wenig Wert darauf legt, die Hygroskopizität der Substanz, destomehr aber, die

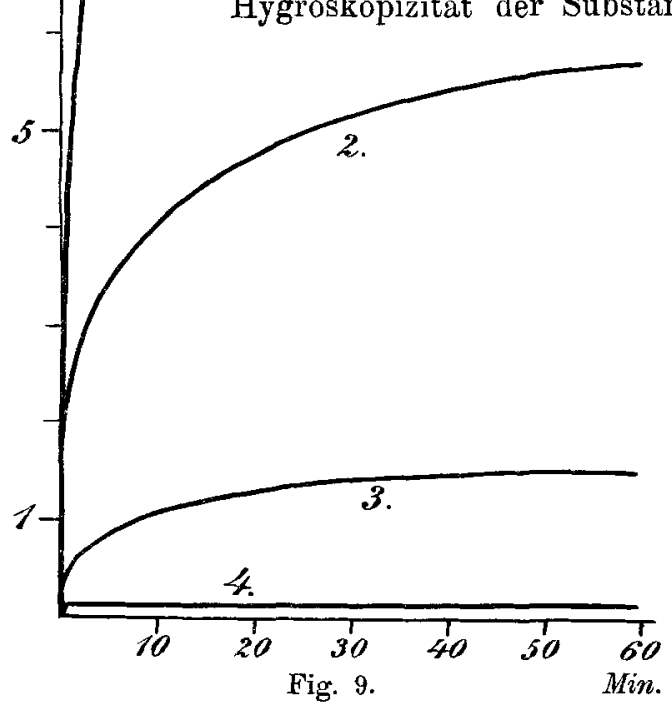

Verwitterung derselben zu beseitigen, und dals dies bei dem rheinischen Spiegelglase in ähnlicher Weise gelungen ist wie bei den Borosilicat - Prismengläsern, welche im Jenaer Glaswerk dargestellt worden sind.

Wieleicht ersichtlich, ist dies auf die günstige Zusammensetzung zurückzuführen, welche bei der Extraktion der Sub. 
stanz die Entstehung dichter von Wasser schwer durchdringlicher Oberflächenschichten bedingt.

$$
\text { Inhalt: }
$$

1. Die Reaktionsfähigkeit starrer Silicatgläser gegen Flüssigkeiten ist nur mit Hilfe frischer Bruchflächen bestimmbar.

2. Die Reaktion mit feuchter ätherischer Jodeosinlösung gibt an Bruchflächen von Glas Veranlassung zur Abscheidung roter Eosin-Alkalischichten, welche zu kolorimetrischen Bestimmungen geeignet sind.

3. Die Untersuchung der Fehlerquellen der "Eosinprobe" ergibt einen mittleren Fehler von wenigstens $5 \%$ des Wertes.

4. Bei kurzer Berührungsdauer (1 Minute) liefert die Eosinprobe Zahlenwerte, welche sich aus einer raschen hydrolytischen Zersetzung des Glases erklären und den ,hygroskopischen Effekten" entsprechen.

5. Die Eosinreaktion wird verlangsamt durch die Bildung alkaliarmer schwer durchlässiger Oberflächenschichten, welche das Glas mehr und mehr „passiv“ machen.

6. Bei resistenten Gläsern ist die Wendung zum passiven Zustand bereits nach 1 Minute Eintauchzeit erreicht.

7. Glasarten, bei welchen der Übergang vom aktiven in den passiven Zustand länger als 1 Stunde dauert, sind hydrolytisch minderwertig.

8. Die „Minutenprobe“ kann als Mafs für die Hygroskopizität der gewöhnlichen Silicatgläser betrachtet werden.

9. Als Mals der Verwitterbarkeit solcher Gläser ist die Minutenprobe nicht genügend, da die erstere nicht von der Hygroskopizität abhängt und mit ihr nicht immer parallel geht.

10. Als relatives Mafs der Verwitterung mehrerer Glasarten lärst sich der Zuwachs der Eosinwerte zwischen einer kurzen. (1 Minute) und einer langen (1 Tag) Berührungszeit betrachten.

Durch zwei derartige Bestimmungen ist jede Glasart hydrolytisch scharf zu kennzeichnen.

11. Bei den leichten optischen Gläsern können die an Bruchflächen bestimmten Eosinwerte auch als mafsgebend für die relative Verwitterbarkeit der geschliffenen Objekte betrachtet werden; das Verhalten der schweren blei- und bariumhaltigen Gläser bleibt noch zweifelhaft.

Charlottenburg, 6. Juni 1907.

Bei der Redaktion eingegangen am 11. Juni 1907. 


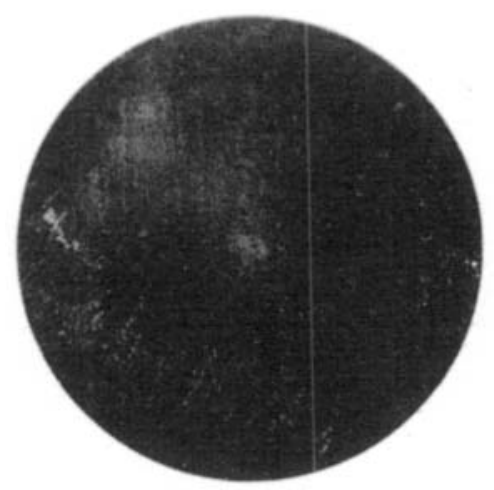

Fig. 1.

Borosilicatkron 0 802

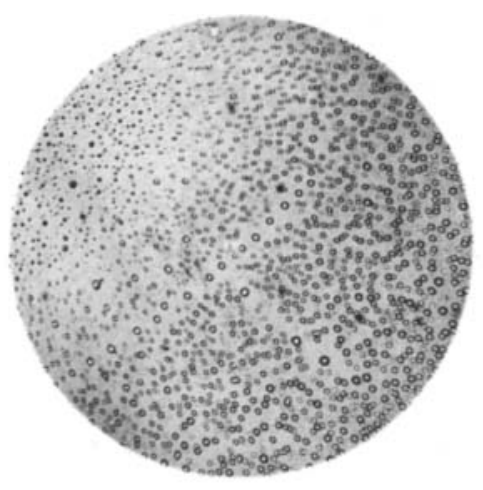

Fig. 3.

Borosilicatkron O $\mathbf{3 4 5 3}$.

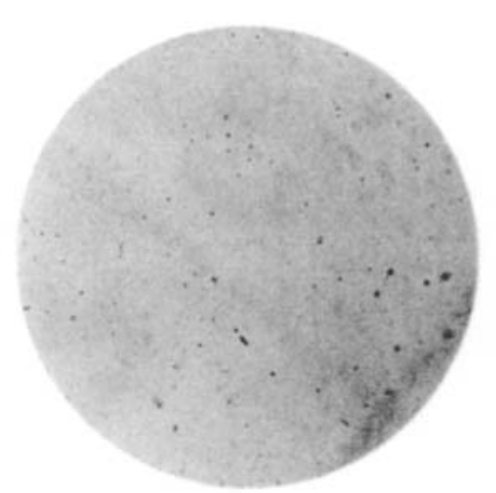

Fig. 2.

Prismenkron 0 3834.

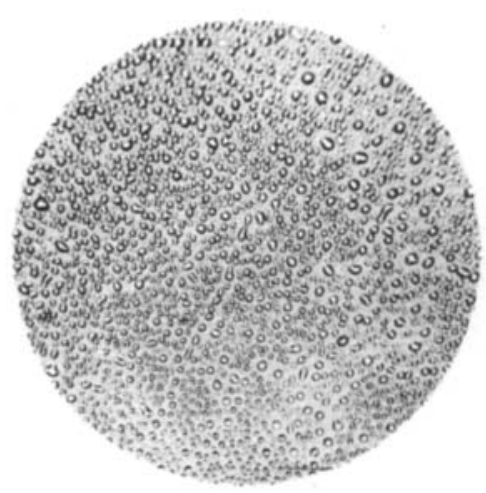

Fig. 4.

Silicatkron $\mathrm{O}$ tio.

Mylius. 